Received: December 1, 2006

\title{
Slowly Progressing Amyotrophic Lateral Sclerosis Caused by H46R SOD1 Mutation
}

\author{
Trygve Holmøy ${ }^{a} \quad$ Kathrine Bjørgo ${ }^{b}$ Per M. Roos ${ }^{c}$ \\ Departments of a Neurology and ${ }^{b}$ Clinical Genetics and ${ }^{c}$ Laboratory of Clinical Neurophysiology, \\ Department of Neurology, Ullevål University Hospital, Oslo, Norway
}

Dear Sir,

We report the first case of familial amyotrophic lateral sclerosis (FALS) caused by H46R SOD1 mutation in a patient of Pakistani descent. H46R SOD1 mutations are associated with a characteristic clinical presentation of slowly progressing paresis of the lower limbs, and the prognosis is much more favorable than in sporadic ALS. The patient presented here

Fig. 1. Marked atrophy of calf muscles and left thigh 28 months after symptom onset.

Fig. 2. H46R mutation in the SOD1 gene. The mutated site is indicated by an arrow (lower panel); the upper panel shows the control sequence. was an athletic man who was able to walk on his hands 2 years after ALS onset, although his walking distance was reduced to $400 \mathrm{~m}$.

\section{Case Report}

A 55-year-old man of Pakistani descent experienced low back pain and paresis of the left leg without pareses in trunk or arm muscles. After 20 months, he could only walk $400 \mathrm{~m}$, but was able to perform 100 push-ups and could walk on his hands. Neurological examination revealed fasciculations, bilateral pareses and atrophy of calf muscles (fig. 1), no sensory deficits, weak tendon reflexes in the legs and positive Babinski sign. MRI of the neuroaxis and routine examination of blood and ce-
1

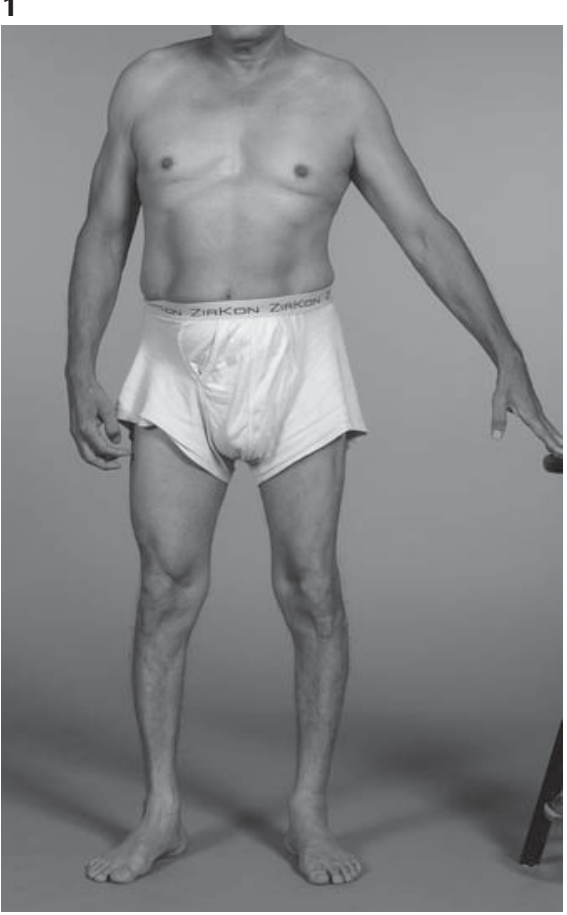

2

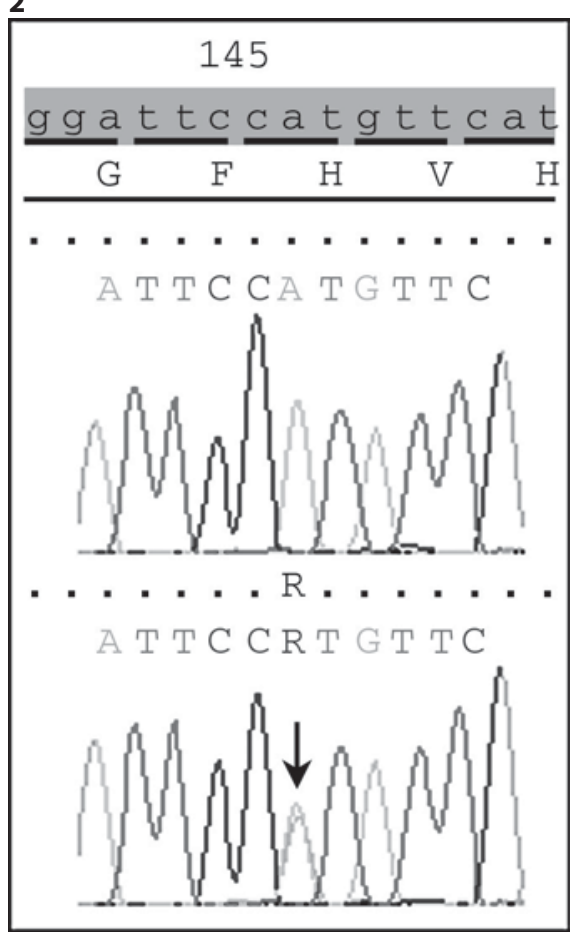

\section{KARGER}

Fax +4161306 1234 E-Mail karger@karger.ch www.karger.com
(C) 2007 S. Karger AG, Basel 0014-3022/07/0581-0057\$23.50/0

Accessible online at: www.karger.com/ene
Trygve Holmøy

Department of Neurology Ullevål University Hospital NO-0407 Oslo (Norway)

Tel. +47 2307 3809, Fax +47 2307 3510, E-Mail trygve.holmoy@medisin.uio.no 
rebrospinal fluid were normal. Neurophysiological examination unveiled normal sensory nerve function, but severely reduced motor amplitudes (0.6-1.0 mA) and moderately reduced motor conduction velocities $(30.4-38.9 \mathrm{~m} / \mathrm{s})$ in tibial and peroneal nerves, along with electromyographic signs of acute denervation in calf and hand muscles.

Eleven relatives in three generations, including his mother, sister and mother's brother, have suffered from slowly progressive paresis, suggesting a diagnosis of FALS. The symptoms have uniformly started in the legs, with survival for 17-21 years. Sequencing of the CuZn SOD1 gene revealed an $\mathrm{A}-\mathrm{G}$ point mutation in exon 2 , resulting in an amino acid substitution of histidine by arginine in position 46 (H46R) (fig. 2).

\section{Discussion}

$\mathrm{H} 46 \mathrm{R}$ is one of 119 known SOD1 mutations which cause FALS $[1,2]$. To our knowledge, this is the first report of $\mathrm{H} 46 \mathrm{R}$ SOD1 mutation in a person of Pakistani descent [Peter M. Andersen, pers. commun.]. FALS constitutes approximately $10 \%$ of ALS. SOD1 mutations have been found in $12-23.5 \%$ of FALS patients, but also in some sporadic ALS patients [2]. Several SOD1 mutations show distinct clinical characteristics. The initial symptom of H46R FALS is leg weakness [3]. Survival is prolonged, and the interval between the presentation of symptoms and respiratory failure usually exceeds 10 years. It is therefore important to recognize the typical clinical picture, and SOD1 sequencing may be necessary to give the patient correct diagnosis and prognosis.

\section{References}

1 Aoki M, Ogasawara M, Matsubara Y, Narisawa K, Nakumara S, Itoyama Y, Abe K: Familial amyotrophic lateral sclerosis (ALS) in Japan associated with $\mathrm{H} 46 \mathrm{R}$ mutation in $\mathrm{Cu} /$ $\mathrm{Zn}$ superoxide dismutase gene: a possible subtype of familial ALS. J Neurol Sci 1994; 126:77-83.

2 Andersen PM: Amyotrophic lateral sclerosis associated with muations in the CuZn superoxide dismutase gene. Curr Neurol Neurosci Rep 2006;6:37-46.

3 Arisato T, Okubo R, Arata H, Abe K, Fukada K, Sakoda S, Shimizu A, Qin XH, Izumo S, Osame M, Nakagawa M: Clinical and pathological studies of familial amyotrophic lateral sclerosis (FALS) with SOD1 H46R mutations in large Japanese families. Acta Neuropathol (Berl) 2003;106:561-568. 